\title{
Biomechanical characteristics analysis of the Salto Forward Tucked Skill as a Start for the Balance Beam Event for the Egyptian national team players in women's gymnastics.
}

\author{
PROF. DR / Lamiaa Ali Mohamed Abdel Rahman
}

Faculty of Physical Education - Helwan University

Researcher / Rania Adel Ali ElSayed

Faculty of Physical Education - Helwan University

\section{Introduction and research problem:}

Among the names of the current era is the era of technology. In all fields, and because of the technological development, science has achieved a great boom and is still stepping in a steady steady pace with rapid steps to achieve further development until science has become the basis in judging the credibility of the various topics, and sport still has a great share of this progress because of the aspiration of their scientists. Scientific progress has played a major role in the advancement and progress of the level of skillful performance in gymnastics, using advanced scientific methods in teaching and training methods.(1:37)

So it was very important to analyze the skill performance of gymnastics skills in a scientific method to know the factors that affect the player's performance through the biomechanics as one of the most important sciences interested in studying and analyzing the player's motor performance, and since the most important goals of sports training are to improve the player's capabilities physically and skillfully to the maximum extent possible. Therefore, workers in the field of sports training need to be familiarized with the information related to the technical aspects of skill performance and the various training and evaluation methods and means because of their positive impact on the level of player performance.(6: 18)

The skill of Salto Forward Tucked is considered as a start of one of the skills of the first group on the balance beam event with a difficulty level (D), which is performed through approaching and then rising on the springboard and then performing a Salto Forward Tucked to land the feet on the balance beam, and the importance of that skill is that it is considered one of the most important skills that can be developed the level of difficulty and consequently an increase in its value, as it can develop its level of difficulty 
from difficulty (D) with a value of (0.4degrees) to difficulty (E) with a value of ( 0.5 degrees) if the player performs the skill with extended knees and body piked. Its difficulty level can also be developed from difficulty (D) to difficulty (F) with a value of (0.6 degrees) if the player performs the skill with winding half a turn around the longitudinal axis, and its difficulty level can also be developed from difficulty (D) to difficulty (G) with a value of ( 0.7 degrees), if the player performed the skill after performing the cartwheel half round off to land with feet on springboard and then made a half turn around the longitudinal axis. Hence, the research problem emerged from a scientific attempt to identify the most important biomechanical characteristics of the skill of Salto Forward Tucked as a start on the balance beam event for the Egyptian women's gymnastics team.

\section{Scientific importance:}

Within the limits of the researcher's knowledge, this study is considered the first of its kind in the Egypt that was conducted on the players of the Egyptian national team for young women, where this study is one of the scientific attempts that provide the workers in the field of gymnastics coaching and technical managers with basic technical information about the performance of the Salto Forward Tucked skill as a start on the balance beam event in women gymnastics in terms of body positions during the technical stages of skill performance, in addition to the quantitative amounts of the most important kinematic and kinetic variables of study skill. The results of this study will be a scientific reference for students and researchers in the field of biomechanics and kinetic analysis in general and the field of gymnastics in particular.

\section{Applied importance:}

This study provides applied contributions to the problems of poor technical performance and the keys to its development through more specific details and more accurate guidance to influence the development and mastery of technical performance in all its details, with recommendations that contribute to develope the technical performance for all stages of the skill (under study), which helps to quickly teach and develop the study skill and saving time and effort during teaching and training progress.

\section{Research objective:}

The aim of the study is to identify the most important biomechanical characteristics of the Salto Forward Tucked skill as a start on the balance beam event in women gymnastics. 


\section{Research question:}

- What are the most important biomechanical properties of the Salto Forward Tucked skill as a start on a balance beam event?

\section{Research Methodology:}

Due to the nature and objectives of the research, the researcher used the experimental approach using the experimental design using the method of pre-post test measurements of the results of the two players (the sample of the research) and the study of the differences in the kinematic paths and the characteristic curves (case study). The researcher also used the descriptive method in analyzing the kinetic paths and the characteristic curves of the model player.

\section{The research sample:}

The research sample was chosen intentionally from the female players of the Egyptian National Junior Team, and the sample is represented by the model player and is the best Egyptian player in terms of correct technical performance of the skill, and the researcher photographed both the model player and the players sample the research sample in the (Pre-post tests) measurements in the performance of the Salto Forward Tucked skill as a start on the balance beam event, and the researcher photographed three attempts, then the researcher selected the best attempt and that analyzed it and extracted the biomechanical variables of performance.

Table (1) : Research sample charecteristics:

\begin{tabular}{l|c|c|c|c}
\hline \multicolumn{1}{c|}{ Variable } & scale & Model player & Player 1 & Player 2 \\
\hline Age & Years & 15 & 12 & 13 \\
\hline Experience & Years & 12 & 9 & 9 \\
\hline Height & cm. & 153 & 160 & 157 \\
\hline Weight & Kgm. & 50 & 53 & 47 \\
\hline
\end{tabular}

\section{Research fields:}

- Time domain: the application spanned from 1-15/8/2019.

- Spatial domain: The Olympic Center for Training National Teams in Maadi, Gymnasium Hall (1) in addition to the scientific laboratory at the Faculty of Physical Education for Boys - Helwan University.

- The human field: the artistic gymnastics female players of the Egyptian National Junior Team.

\section{Research tools:}




\section{1- Imaging devices and tools:}

- Two video cameras (8mm.) with a frequency of (25) images per second.

- Two tripods with water scale.

- Monitor video processing unit.

- Indicative control marks.

- Measure tape (meters).

- Two videos of $(8 \mathrm{ml})$ ore.

- Fast light source (flash).

- Orthogonal calibration system $(150 \mathrm{~cm}$ x $150 \mathrm{~cm} \mathrm{x} 150 \mathrm{~cm})$.

- An electrical connection.

- A legal springboard.

- Legal balance beam.

\section{2- Kinematographic analysis devices and tools.}

- IBM brand computer (64GB memory, 4.3GB hard disk, MMX 233 motherboard).

- Brand video card.

- Kinetic analysis program.

\section{Steps to perform the research:}

\section{1 - The first exploratory study:}

The researcher conducted the first exploratory study from 1/8/2019 to $8 / 15 / 2019$ with the aim of:

- Ensure the validity of shooting location.

- Determine the most appropriate time for photography.

- Determine the location of the cameras, height, and the shooting angles.

- Detect problems that may arise during the basic experiment.

- Training of helpers.

- Ensure that the imaging is valid for analysis.

\section{2- The second exploratory study:}


The researcher conducted the second exploratory study in the period from $15 / 8 / 2019$ to $29 / 8 / 2019$, with the aim of:

- Validity and suitability of training location.

- Validity and suitability of training location.

- Suitability of training location.

- Suitable for specific exercises.

- Determine the proposed distances to perform each exercise.

- Determine the appropriate repetitions for each exercise.

- Determine the appropriate rest intervals for each exercise.

- Determine the time of training exercises during the unit.

\section{3- Videographic shooting and biomechanical analysis:}

- Components of the three-dimensional kinetic analysis program:

- (IBM) computer.

- 64MB memory, 80GB hard disk, PIII 450

- ATI card (in / Out).

- Sony video camera + VHS HI 8mm tape

- Photography processing unit (Camera or Monitor)

\section{Features of the motor analysis program (MotionTrak):}

This program is registered at the Information Systems Center of the Academy of Scientific Research under No. 665/5 on 23/5/2001. On the authority of Dr. Mostafa Atwa, Professor of Biomechanics and Mathematical Movement Science at the Faculty of Physical Education in Sadat, at Sadat City University.

\section{Program Calibration Unit:}

This program can read any unit for calibration of length information in nature visible inside the staff, and in it the calibration system is stored in the computer memory for each camera separately, which is a device that crosses its dimensions as follows: $0.50 \mathrm{~m} \times 0.50 \mathrm{~m} \times 0.50 \mathrm{~m}$ and the role of determining distances in nature from the cadres. 


\section{Potentials of the program:}

The program performs the necessary kinetic analysis of any motor skill (linear-rotational-complex) and we can obtain a number of biomechanical variables for the body as a whole and for each part of the body during every moment of performance and in the directions $(x, y, z, x y, z y, z x, z y x)$ which is represented in (temporal analysis) which contains the temporal distribution of each locality of the performance, (mechanical analysis) that contains the distance, displacement, speed, wheel, angle of the joints, and the angles of inclination of the parts at the horizontal level, and the speed The angle, the angle wheel and (kinetic analysis) are represented by the energy of the position, the movement energy, the force, the work, the power, the torque, the centrifugal force, the amount of movement, the amount of the angular movement, the rotational failure.

\section{-Analysis Procedures:}

\section{A- videograpgic and storing processes:}

Review the videograpgic processes to send them to the computer that contains the MotionTrak program via USB, and after storing the movie inside the computer, it is called on the program to determine the period duration which the attemp analysis will start and end. 


\section{B- Specifications of analysis:}

During the different stages of performance, the reference points of the sample's body were selected and numbered 17 points (head, right front metacarpal, right wrist, right elbow, right shoulder joint, and the same points on the left arm, the right front metatarsal, right knee, right hip joint, and the same points on the left leg) respectively, and defined in the program (Atwaa model) to determine the body center of gravity and its parts and the other kinetic and kinetic variables by mathematical treatments, where the center of gravity is estimated using the relative distribution of centers of gravity of the parts, as well as the relative weight of the parts as a percentage of the total body weight by (James H. Hay 1985), citing Clawser.

\section{Program outputs:}

\section{First: Stick Figures:}

We get the stick figures in three levels: the side plane $x y$, the front plane zy, and the horizontal plane $x z$ (for each part of the body separately, head and torso, legs, arms, shoulder line, The pelvic line, shoulder to pelvis line), in stick figures that express movement during the entire stages of movement.

\section{Second: The numerical data report:}

Through this report, we obtain all numeric data (kinematic or kinetic variables) of the movement analyzed, in three-dimensional or twodimensional directions (for each part of the body separately : head, trunk, legs, arms) in the form of tables during all stages of movement.

\section{Third: Graphs:}

Through this output we get all curves, whether for (kinematic or kinetic variables) of the movement analyzed, in the three-dimensional or twodimensional directions, (for each part of the body separately : head, trunk, legs, arms) in the form of a graph during all stages of movement.

\section{4 - Videographic of the model player:}


The researcher conducted the videography of the model player on Saturday $10 / 8 / 2019$ in gymnasium hall (1) for the Olympic Center for National Teams, and the researcher conducted the analysis process.

Through the results of the analysis and the researcher's review to the scientific references and the experience of the researcher, she determined the technical description of the skill (Salto Forward Tucked) as a start on the balance beam event. And the researcher suggested the exercises used in the program through the results of the biomechanical analysis.

\section{The kinematic variables:}

Through the biomechanical analysis of the skill (Salto Forward Tucked) as a start on the balance beam event, and through performance requirements, research objectives and its questions, the researcher has determined the variables' characteristics of the skill (Salto Forward Tucked) as a start on the balance beam event:

- The time distribution of the performance stages.

- Vertical horizontal distance of center of gravity and metatarsal.

- Angular change (hip - shoulder - knee).

- The center of gravity angle.

- The angle of flight of the center of gravity.

- The resulted velocity of center of gravity.

\section{Statistical treatments:}

The researcher used the raw results extracted from the biomechanical analysis of the study variables and presented them through the appropriate charts and graphs for each variable to display and discuss the research results.

\section{Results presentation and discussion:}


Table (2) : Time distribution of movement stages of Salto Forward Tucked skill as a start on the balance beam event in female gymnastics - (model player)

\begin{tabular}{l|c|c|c|c}
\hline \multirow{2}{*}{ Technical stages } & \multicolumn{4}{|c}{ Model player } \\
\cline { 2 - 5 } & photos & number of & time & percentage \\
\cline { 2 - 5 } & $($ From - to) & phots & sec. & $\%$ \\
\hline Step to single leap & $(1-6)$ & 6 & 0.33 & 0.15 \\
\hline Push off the springboard & $(7-9)$ & 3 & 0.2 & 0.09 \\
\hline Flying to front turn & $(10-17)$ & 8 & 0.54 & 0.24 \\
\hline Landing and balance & $(18-35)$ & 18 & 1.2 & 0.53 \\
\hline Total & & & 2.27 & 1 \\
\hline
\end{tabular}

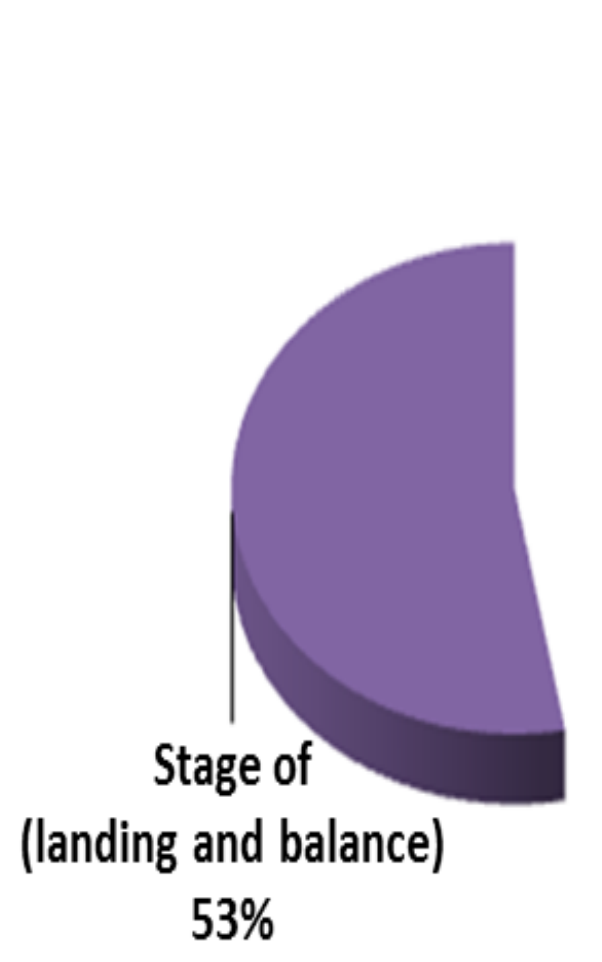

\section{Stage of (Step to single leap)}

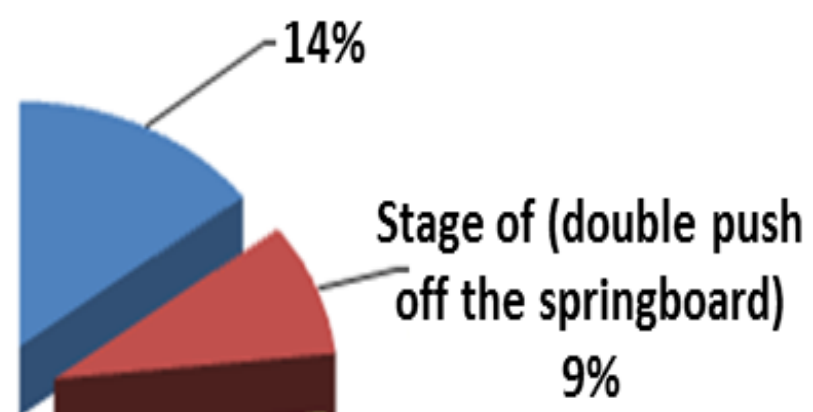

Stage of

$53 \%$

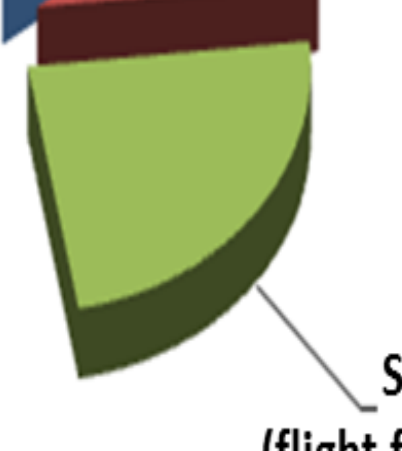

Stage of

(flight for front turn) $24 \%$ 
Graph (1) : Time distribution of movement stages of Salto Forward Tucked skill as a start on the balance beam event in female gymnastics - (model player)

It is clear from Table (2) that the skill included four stages which are the stage of single leap, the stage of double push off the sprigboard, the stage of flight and forward turn, the stage of landing and balance where each stage took time over (0.33), (0.2), (0.54), (1.2) seconds respectively, where the contribution percentages of those stages in this skill were (15\%), (9\%), (24\%), (53\%), respectively. The researcher attributes these results to the importance of landing and balance stage, where the deductions degree is big after false execution during performance in this stage and affects the total score of the player.

Table (3) Horizontal and vertical distance (body center of gravity - left and right foot) of Salto Forward Tucked skill as a start on the balance beam event in female gymnastics - (model player)

\begin{tabular}{|c|c|c|c|c|c|c|c|c|}
\hline \multirow[b]{2}{*}{ Stages } & \multirow[b]{2}{*}{ Photos } & \multirow[b]{2}{*}{ Time } & \multicolumn{2}{|c|}{ gravity Center of } & \multicolumn{2}{|c|}{ Right foot } & \multicolumn{2}{|c|}{ Left foot } \\
\hline & & & $\begin{array}{c}\text { Horizontal } \\
\text { distance }\end{array}$ & $\begin{array}{l}\text { Vertical } \\
\text { distance }\end{array}$ & $\begin{array}{c}\text { Horizontal } \\
\text { distance }\end{array}$ & $\begin{array}{l}\text { Vertical } \\
\text { distance }\end{array}$ & $\begin{array}{c}\text { Horizontal } \\
\text { distance }\end{array}$ & $\begin{array}{l}\text { Vertical } \\
\text { distance }\end{array}$ \\
\hline \multirow{6}{*}{ 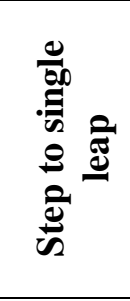 } & 1 & $\mathbf{0}$ & -2.03 & 0.69 & -2.03 & 0.17 & -2.08 & -0.23 \\
\hline & 2 & 0.07 & -1.81 & 0.62 & -1.66 & 0.07 & -1.98 & -0.28 \\
\hline & 3 & 0.13 & -1.49 & 0.7 & -1.11 & 0.04 & -1.94 & -0.1 \\
\hline & 4 & 0.2 & -1.19 & 0.84 & -0.8 & 0.01 & -1.43 & -0.09 \\
\hline & 5 & 0.27 & -0.92 & 0.74 & -0.33 & 0.06 & -0.56 & 0.2 \\
\hline & 6 & $\mathbf{0 . 3 3}$ & -0.61 & 0.68 & -0.1 & -0.02 & -0.16 & 0.09 \\
\hline \multirow{3}{*}{ 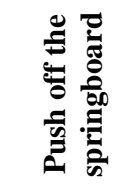 } & 7 & 0.4 & -0.29 & 0.61 & 0.11 & -0.22 & 0.12 & -0.24 \\
\hline & 8 & 0.47 & -0.08 & 0.62 & 0.16 & -0.27 & 0.16 & -0.24 \\
\hline & 9 & 0.53 & 0.03 & 0.78 & 0.03 & -0.22 & 0.07 & -0.22 \\
\hline \multirow{7}{*}{ 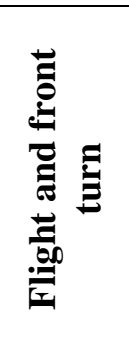 } & 10 & 0.6 & 0.19 & 1.01 & -0.06 & 0.03 & -0.15 & 0.1 \\
\hline & 11 & 0.67 & 0.37 & 1.11 & -0.19 & 0.33 & -0.29 & 0.6 \\
\hline & 12 & 0.73 & 0.49 & 1.22 & -0.24 & 1.03 & -0.16 & $\mathbf{1 . 3 1}$ \\
\hline & 13 & 0.8 & 0.54 & 1.34 & 0.2 & 1.86 & $\begin{array}{l}0.03 \\
\end{array}$ & 1.72 \\
\hline & 14 & $\begin{array}{l}\mathbf{0 . 8 7} \\
\end{array}$ & 0.65 & 1.43 & 0.69 & 2.04 & 0.46 & 1.98 \\
\hline & 15 & $\mathbf{0 . 9 3}$ & 0.89 & 1.5 & 1.39 & 1.79 & 1.14 & 1.98 \\
\hline & 16 & 1 & 1.11 & 1.43 & 1.71 & 1.03 & 1.76 & 1.43 \\
\hline
\end{tabular}




\begin{tabular}{|c|c|c|c|c|c|c|c|c|}
\hline & 17 & 1.07 & 1.25 & 1.31 & 1.63 & 0.77 & 1.88 & 0.89 \\
\hline \multirow{18}{*}{ 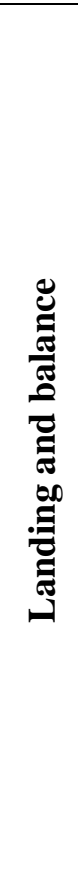 } & 18 & 1.13 & 1.51 & 1.41 & 1.63 & $\mathbf{0 . 8 3}$ & 1.9 & $\mathbf{0 . 8 3}$ \\
\hline & 19 & 1.2 & 1.55 & 1.31 & 1.68 & $\begin{array}{l}0.88 \\
\end{array}$ & 1.96 & 0.85 \\
\hline & 20 & 1.27 & 1.64 & 1.34 & 1.67 & $\begin{array}{l}0.88 \\
\end{array}$ & 2 & $\mathbf{0 . 8 7}$ \\
\hline & 21 & 1.33 & 1.7 & 1.4 & 1.68 & 0.84 & 2 & 0.88 \\
\hline & 22 & 1.4 & 1.71 & 1.46 & 1.67 & 0.84 & 1.95 & $\mathbf{0 . 8 5}$ \\
\hline & 23 & 1.47 & 1.76 & 1.53 & 1.75 & 0.82 & 1.97 & 0.82 \\
\hline & 24 & 1.53 & 1.75 & 1.74 & 1.84 & 1.1 & 1.86 & 1.1 \\
\hline & 25 & 1.6 & 1.84 & 1.65 & 2.11 & $\mathbf{0 . 9 3}$ & 1.94 & 0.92 \\
\hline & 26 & 1.67 & 1.87 & 1.67 & 2.21 & 0.92 & 1.92 & $\mathbf{0 . 8 9}$ \\
\hline & 27 & 1.73 & 1.88 & 1.68 & 2.19 & 0.87 & 1.94 & 0.87 \\
\hline & 28 & 1.8 & 1.9 & 1.7 & 2.16 & $\begin{array}{l}0.89 \\
\end{array}$ & 1.92 & 0.86 \\
\hline & 29 & 1.87 & 1.95 & 1.74 & 2.27 & 0.89 & 1.94 & $\mathbf{0 . 8 9}$ \\
\hline & 30 & 1.93 & 1.99 & 1.81 & 2.24 & $\mathbf{0 . 8 9}$ & 1.97 & $\mathbf{0 . 8 9}$ \\
\hline & 31 & 2 & 1.95 & 1.82 & 2.22 & 0.89 & 1.96 & $\mathbf{0 . 8 3}$ \\
\hline & 32 & 2.07 & 2.01 & 1.85 & 2.21 & 0.89 & 1.94 & 0.89 \\
\hline & 33 & 2.13 & 1.99 & 1.86 & 2.15 & 0.91 & 1.93 & 0.94 \\
\hline & 34 & 2.2 & 1.95 & 1.78 & 2.19 & 0.88 & 1.93 & 0.91 \\
\hline & 35 & 2.27 & 1.98 & 1.73 & 2.26 & 0.84 & 1.97 & $\mathbf{0 . 8 3}$ \\
\hline
\end{tabular}
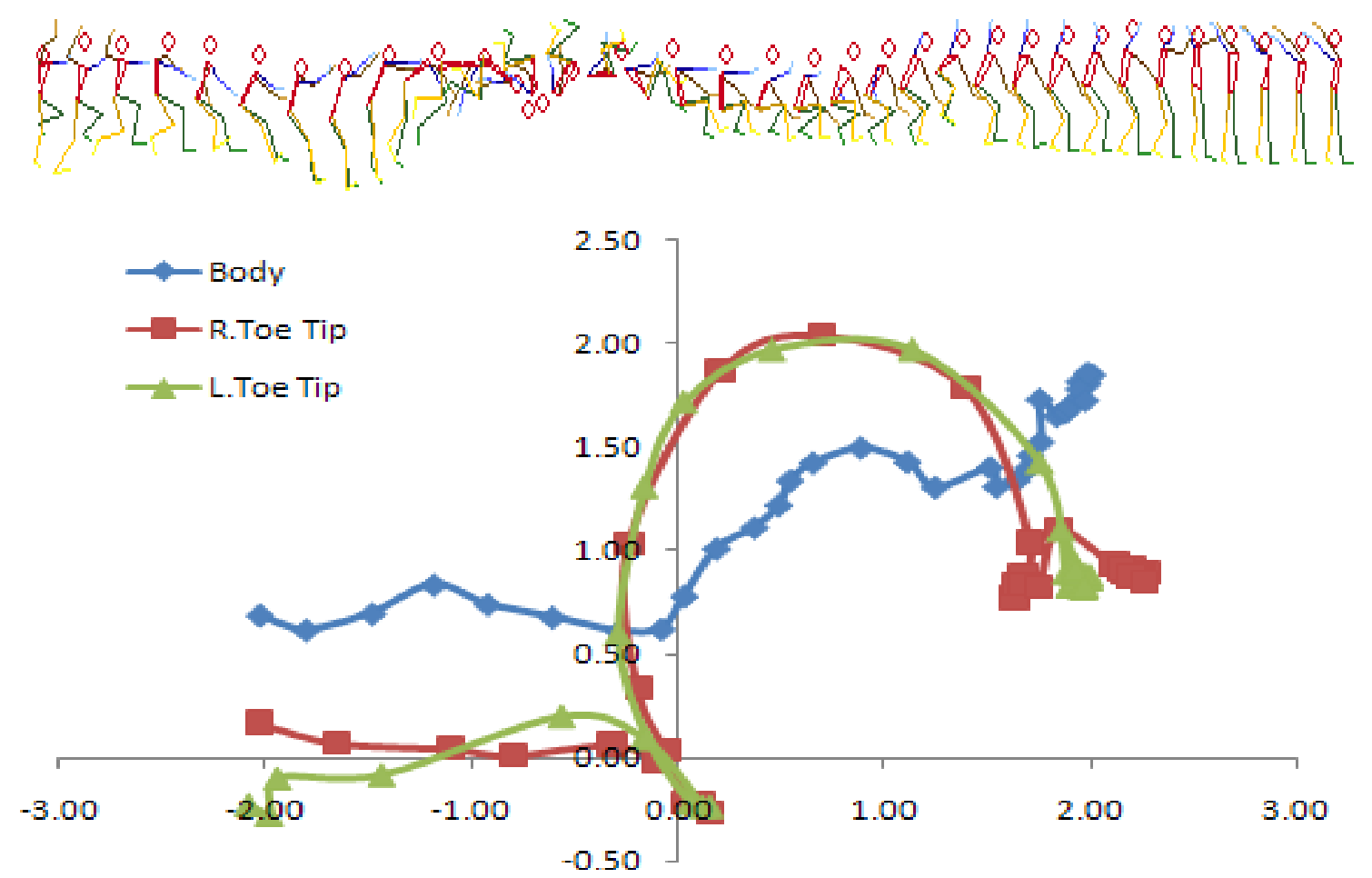

Figure (2) : The kinematic path of (center of gravity of the body - the left and right instep) of Salto Forward Tucked skill as a start on the balance beam event in female gymnastics - (model player) 
It is clear from Table (3) that the horizontal distance in the stage of step to single leap to the moment of reliance on the springboard has reached $(2.03 \mathrm{~m}$.) where it took time to stand on the springboard during pushing off with feet by a time of $(0.2 \mathrm{sec}$.). In the stage of flight to do Salto Forward Tucked, the maximum height of center of gravity of the body has reached $(1.50 \mathrm{~m}$.) and was at a distance from the springboard has reached $(0.89 \mathrm{~m}$.$) ,$ while the distance from the springboard at the moment of pushing off to landing on the balance beam has reached $(1.98 \mathrm{~m}$.).

The researcher believes that the model player made the Salto Forward Tucked in the middle of the distance between the springboard and the landing area on the balance beam, where the height of the foot during the transition from the ground to the springboard was $(0.33 \mathrm{~m}$.), while the distance between the metatarsal feet (right / left) at the moment of landing on the balance beam was $(0.27 \mathrm{~cm})$.

Table (4) Angular Change (Shoulder - Hip - Knee - Center of Gravity in Horizontal) during a performance of (Salto Forward Tucked skill as a start) on the balance beam event in female gymnastics - (model player)

\begin{tabular}{|c|c|c|c|c|c|c|c|}
\hline \multirow{7}{*}{ 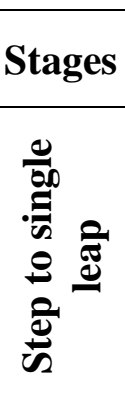 } & \multirow{2}{*}{$\begin{array}{c}\text { Photos } \\
1 \\
\end{array}$} & \multirow{2}{*}{$\begin{array}{c}\text { Time } \\
0 \\
\end{array}$} & \multirow{2}{*}{$\begin{array}{c}\text { Shoulder } \\
160.29\end{array}$} & \multirow{2}{*}{$\begin{array}{c}\text { Hip } \\
119.89\end{array}$} & \multirow{2}{*}{$\begin{array}{l}\text { Knee } \\
45.28\end{array}$} & \multicolumn{2}{|c|}{$\begin{array}{c}\text { Center of gravity in } \\
\text { Horizontal }\end{array}$} \\
\hline & & & & & & 18.77 & -15.3 \\
\hline & 2 & 0.07 & 131.93 & 109.76 & 59.88 & 18.9 & -18.2 \\
\hline & 3 & 0.13 & 99.1 & 102.28 & 94.36 & 25.14 & 14.29 \\
\hline & 4 & 0.2 & 92.84 & 118.7 & 108.43 & 35.23 & 26.57 \\
\hline & 5 & 0.27 & 0.47 & 108.76 & 134.77 & 38.77 & -21.15 \\
\hline & 6 & 0.33 & 78.08 & 84.26 & 139.52 & 48.11 & -11.08 \\
\hline \multirow{3}{*}{ 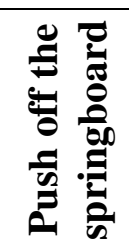 } & 7 & 0.4 & 81.47 & 118.25 & 143.07 & 64.76 & -12.51 \\
\hline & 8 & 0.47 & 112.76 & 125.69 & 147.16 & 82.59 & 2.73 \\
\hline & 9 & 0.53 & 115.48 & 130.37 & 163.17 & 87.8 & 82.64 \\
\hline \multirow{7}{*}{ 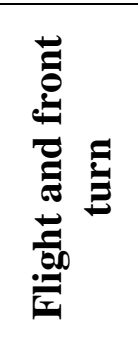 } & 10 & 0.6 & 112.22 & 113.4 & 150.64 & 79.53 & 80.95 \\
\hline & 11 & 0.67 & 54.72 & 77.42 & 107.75 & 71.63 & 31.73 \\
\hline & 12 & 0.73 & 33.34 & 58.53 & 66.26 & 68.23 & 52.31 \\
\hline & 13 & 0.8 & 19.9 & 94.21 & 55.89 & 67.92 & 136.86 \\
\hline & 14 & 0.87 & 26.97 & 74.03 & 52.86 & 65.38 & 46.75 \\
\hline & 15 & 0.93 & 13.79 & 59.19 & 45.74 & 59.43 & 16.68 \\
\hline & 16 & 1 & 37.62 & 59.61 & 46.1 & 52.14 & -18.2 \\
\hline
\end{tabular}




\begin{tabular}{c|c|c|c|c|c|c|c}
\hline & 17 & 1.07 & 47.67 & 94.51 & 75.2 & 46.39 & -48.88 \\
\hline \multirow{4}{*}{} & 18 & 1.13 & 50.82 & 80.95 & 49.19 & 42.86 & 21.96 \\
\cline { 2 - 8 } & 19 & 1.2 & 65.19 & 55.99 & 46.34 & 40.34 & -142.76 \\
\cline { 2 - 8 } & 20 & 1.27 & 54.87 & 60.51 & 30.02 & 39.26 & 19.09 \\
\cline { 2 - 8 } & 21 & 1.33 & 65.53 & 66.93 & 41.49 & 39.55 & 57.23 \\
\cline { 2 - 8 } & 22 & 1.4 & 63.36 & 73.09 & 50.61 & 40.53 & 43.36 \\
\cline { 2 - 8 } & 23 & 1.47 & 66.8 & 81.71 & 63.84 & 40.98 & 80.08 \\
\cline { 2 - 8 } & 24 & 1.53 & 93.84 & 60.55 & 95.34 & 44.69 & -85.98 \\
\cline { 2 - 8 } & 25 & 1.6 & 72.36 & 84.03 & 111.93 & 42 & -57.14 \\
\cline { 2 - 8 } & 26 & 1.67 & 61.95 & 96.33 & 128.94 & 41.8 & 38.19 \\
\cline { 2 - 8 } & 27 & 1.73 & 70.13 & 97.02 & 129.24 & 41.66 & 57.29 \\
\cline { 2 - 8 } & 28 & 1.8 & 53.98 & 112.67 & 128.29 & 41.81 & 57.29 \\
\cline { 2 - 8 } & 29 & 1.87 & 71.54 & 127.23 & 143.75 & 41.86 & 45.81 \\
\cline { 2 - 8 } & 30 & 1.93 & 88.44 & 143.6 & 151.64 & 42.33 & 100.1 \\
\cline { 2 - 8 } & 31 & 2 & 94.62 & 173.53 & 171.97 & 43.04 & -14.32 \\
\cline { 2 - 8 } & 32 & 2.07 & 115.22 & 171.5 & 170.15 & 42.64 & 28.64 \\
\hline \multirow{5}{*}{} & 33 & 2.13 & 127.37 & 174.94 & 179.26 & 43.12 & -28.65 \\
\cline { 2 - 8 } & 34 & 2.2 & 131.95 & 170.26 & 172.75 & 42.5 & 114.35 \\
\cline { 2 - 8 } & 35 & 2.27 & 123.75 & 159.86 & 176.02 & 41.2 & -95.41 \\
\hline
\end{tabular}
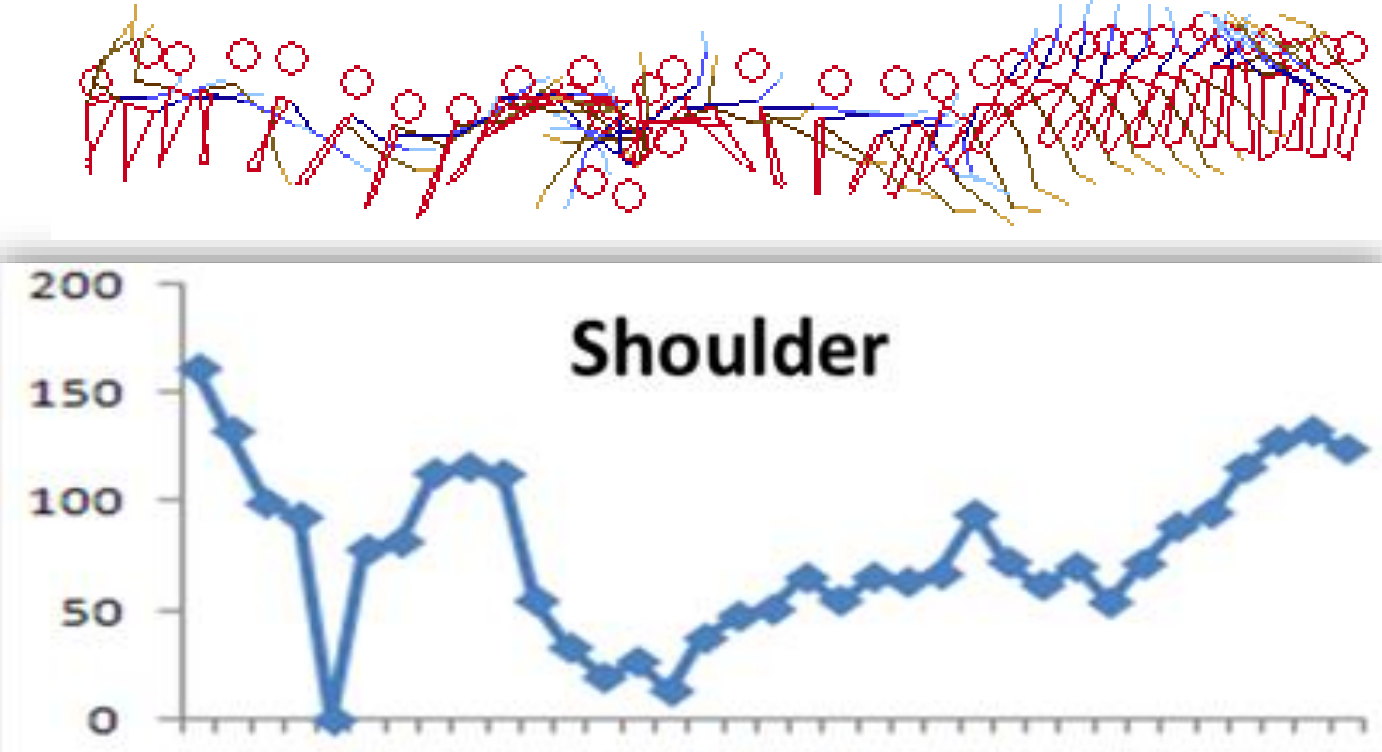

1357911131517192123252729313335

Figure (3): The angular curve (shoulder) during a performance of (Salto Forward Tucked skill as a start) on the balance beam event in female gymnastics - (model player)

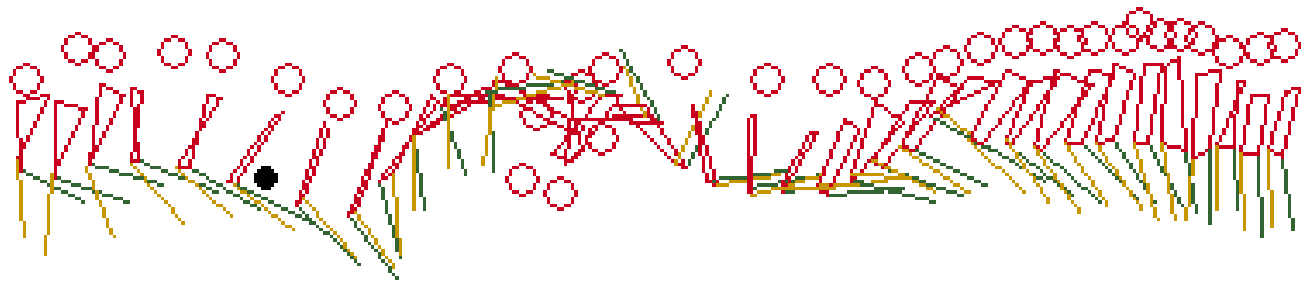




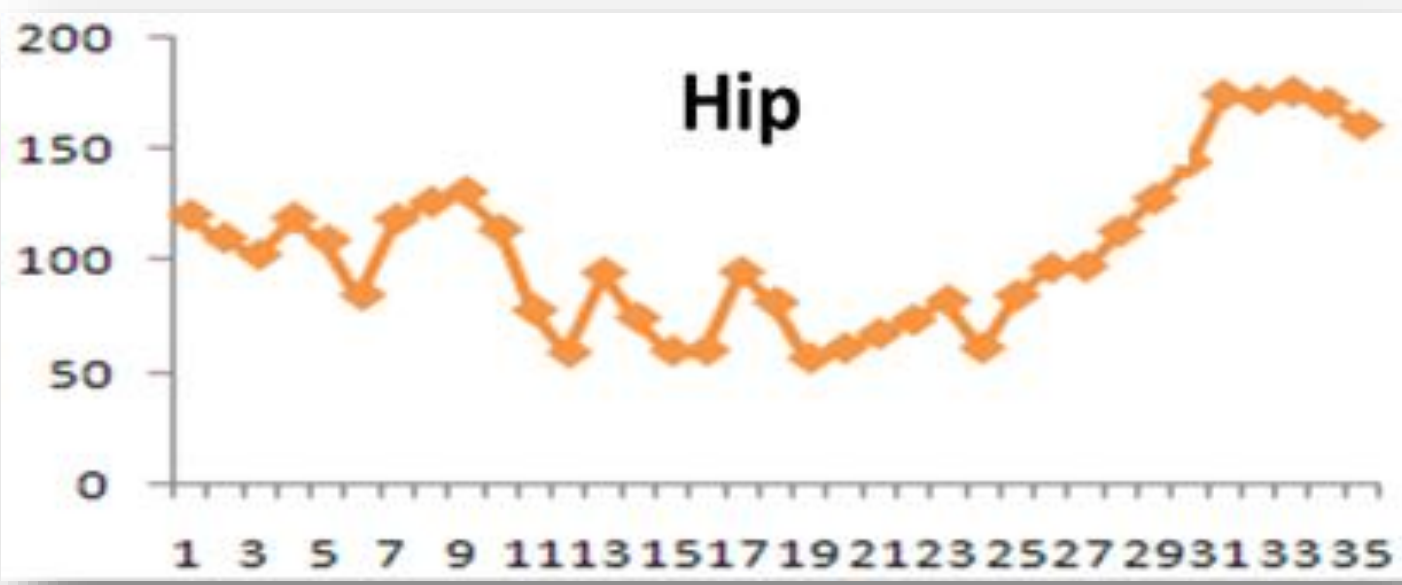

Figure (4): The angular curve (Hip) during a performance of (Salto Forward Tucked skill as a start) on the balance beam event in female gymnastics $\left(m^{-1+1}+1-\cdots\right)$
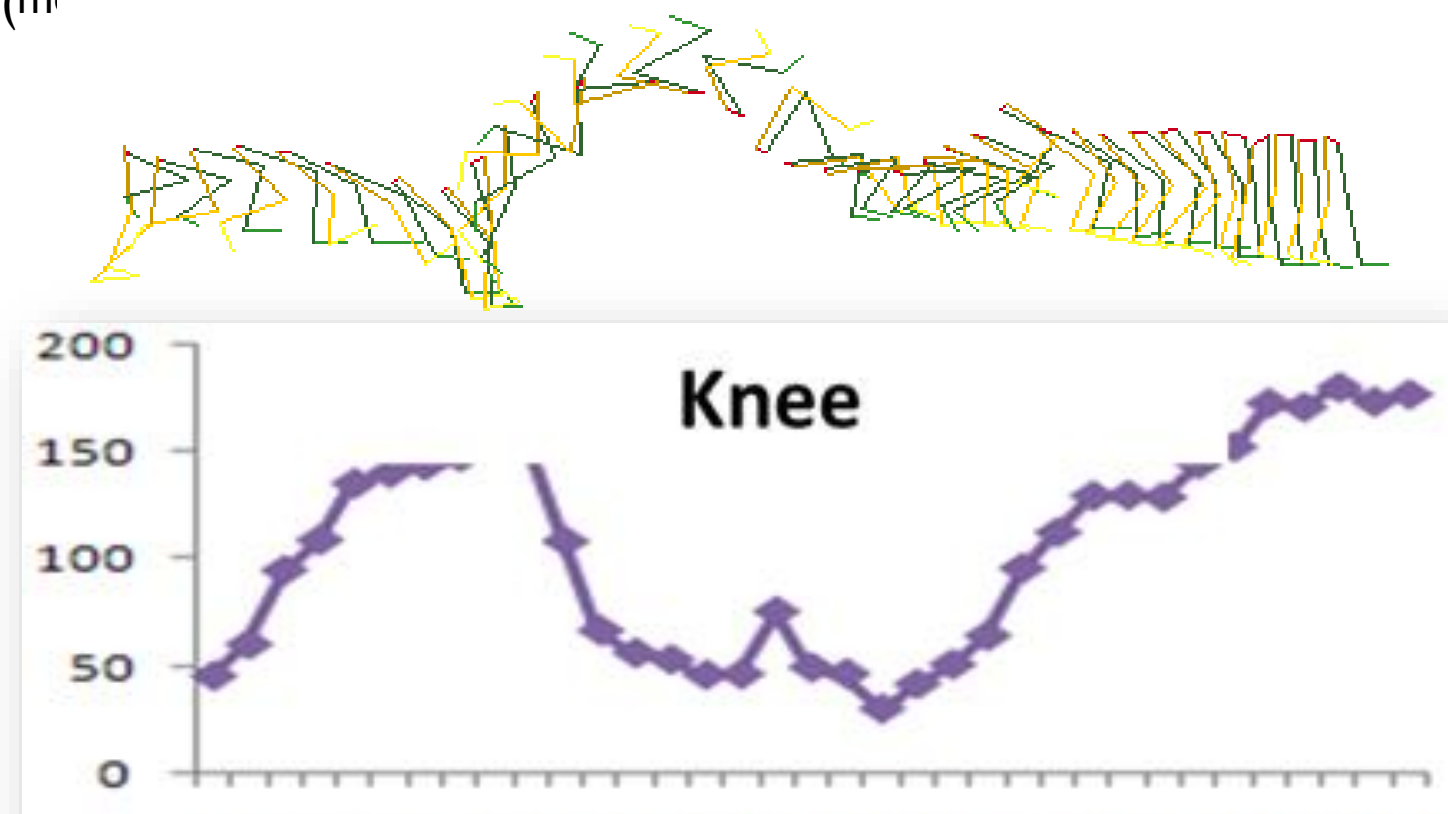

1357911131517192123252729313335

Figure (5): The angular curve (Knee) during a performance of (Salto Forward Tucked skill as a start) on the balance beam event in female gymnastics - (model player).

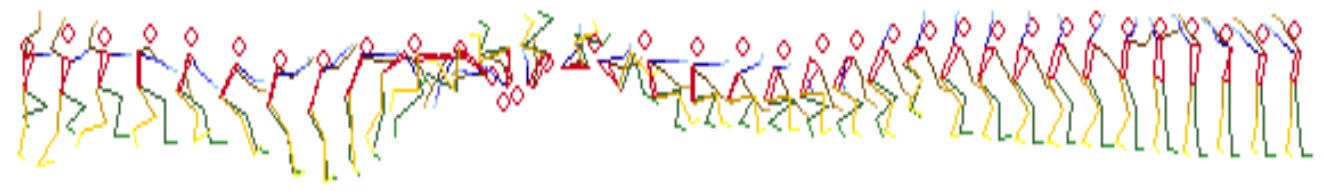




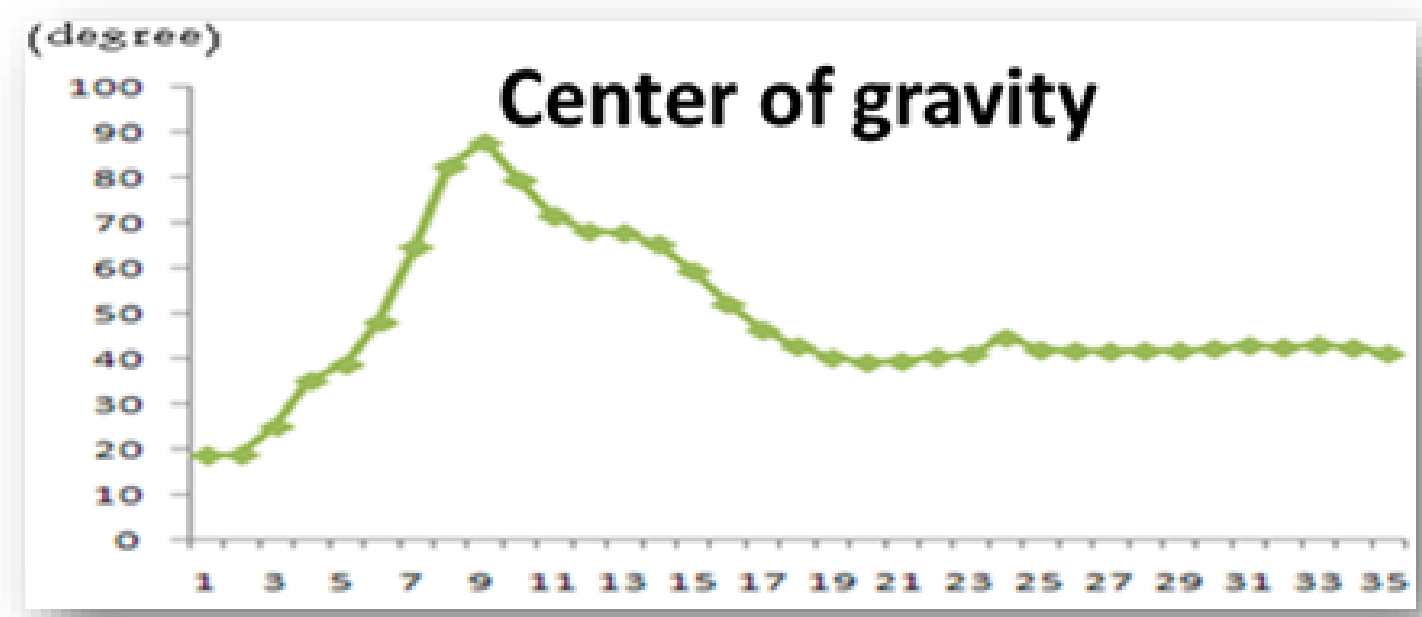

Figure (6): The angular curve (Center of gravity in Horizontal) during a performance of (Salto Forward Tucked skill as a start) on the balance beam event in female gymnastics - (model player).

79.30

87.70

degtee $\quad 64.51$

degree

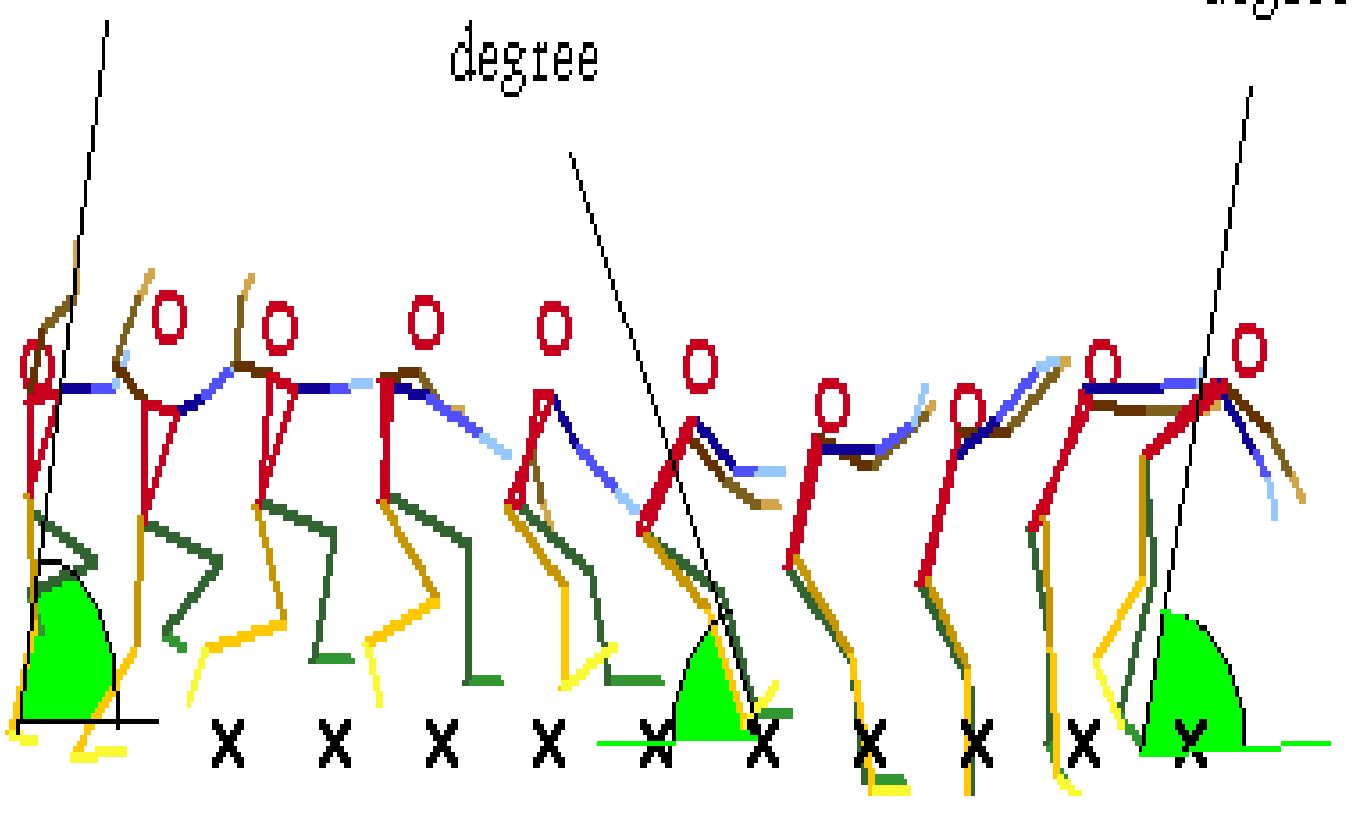


Figure (7): The entry and exit angles of the land and the springboard

It is also clear from Table (4) that the inclination angle of the body on the ground can be recognized at the moment of single leap through the horizontal and vertical dimensions of the body center of gravity and the right and left instep has reached (79.30 degrees), and the inclination angle of the body on the ground at the moment (Entry- Exit) from the springboard and double push off have reached $(64.51,87.70$ degrees) respectively.

The researcher believes that the body at the moment of exit, whether from the ground or the springboard, is almost perpendicular, while entering on the springboard is approximately less than the vertical position by about (30 degrees) and the body is in the form of an angle from the hip joint, so that the body is in a position that allows it to perform the movement properly and maintain The appropriate angle is the body parts without getting any degrees' decreases in player's total performance score.

Table (5): Summary of Angular Change of Shoulder - Hip - Knee - Body's center of gravity (Model player)

\begin{tabular}{l|c|c|c|c}
\hline \multicolumn{1}{c|}{ Photos } & Shoulder & Hip & Knee & $\begin{array}{c}\text { Center of } \\
\text { gravity in } \\
\text { Horizontal }\end{array}$ \\
\hline $\begin{array}{l}\text { The moment of } \\
\text { leaving the land (1) }\end{array}$ & 160.29 & 119.89 & 45.28 & 60.42 \\
\hline $\begin{array}{l}\text { The moment of } \\
\text { entering the } \\
\text { springboard (7) }\end{array}$ & 81.47 & 118.25 & 143.07 & 12.51 \\
\hline $\begin{array}{l}\text { The moment of } \\
\text { leaving the } \\
\text { springboard (9) }\end{array}$ & 115.48 & 130.37 & 163.17 & 82.64 \\
\hline
\end{tabular}




\begin{tabular}{l|l|l|l|l}
\hline $\begin{array}{l}\text { Moment of lower } \\
\text { hip flexion (12) }\end{array}$ & 33.34 & 58.53 & 66.26 & \\
\hline $\begin{array}{l}\text { Moment of } \\
\text { collision of the } \\
\text { balance beam (18) }\end{array}$ & 50.82 & 80.95 & 49.19 & 21.96 \\
\hline $\begin{array}{l}\text { Lowest knee } \\
\text { flexion on the } \\
\text { balance beam (20) }\end{array}$ & 54.87 & 60.51 & 30.02 & \\
\hline $\begin{array}{l}\text { The moment of } \\
\text { stand-up and } \\
\text { balance (35) }\end{array}$ & 123.75 & 159.86 & 176.02 & 95.41 \\
\hline
\end{tabular}

It is clear from Table (5) that the angles of the shoulder, hip, knee and center of gravity in horizontal at the moment of leaving the ground (1) have reached (160.29), (119.89), (45.28) and (60.42) degrees, respectively, while at the moment of entering the springboard (7) they reached (81.47), (118.25), (143.07), (12.51) degrees respectively, while at the moment of leaving for peace (9) they reached (115.48), (130.37), (163.17), (82.64) degrees respectively, and at the moment of the lowest bending of the hip in rotation (12) have reached (33.34), (58.53), (66.26), and at the moment of collision on the balance beam (18) have reached (50.82), (80.95), (49.19), (21.96) degrees respectively, and in the slightest bend of the knee on the balance beam (20) they have reached (54.87), (60.51), (30.02), and at the moment of standing and balance (35) they have reached (123.75), (159.86), (176.02), (95.41) degrees respectively.

With reference to the angle of the body's center of gravity at the moment (exit of the ground), (and entering on the springboard), (exit from the springboard) have reached (60.42), (12.51), (82.64) degrees respectively, 
while for a moment of collision with the balance beam was (21.96) and when standing it was (95.41) degrees.

The researcher believes that the corners of the hip and knee at the moment of leaving the ground have helped the player to perform the appropriate leap of the player's body and fly to do the Salto Forward Tucked skill as a start and land on the balance beam in the proper way to perform the following movements.

Table (6) : The resulted speed (of the body's center of gravity) during the performance of a skill (Salto Forward Tucked as a start) on the balance beam event - in female gymnastics - (model player)

\begin{tabular}{|c|c|c|c|}
\hline Stages & Photos & Time & Resulted speed \\
\hline \multirow{5}{*}{ 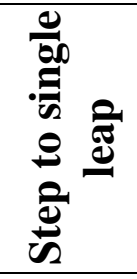 } & $1->2$ & 0.07 & 0 \\
\hline & $2->3$ & 0.13 & 3.55 \\
\hline & $3->4$ & 0.2 & 4.95 \\
\hline & $4->5$ & 0.27 & 4.97 \\
\hline & $5->6$ & 0.33 & 4.17 \\
\hline \multirow{3}{*}{ 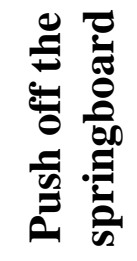 } & $6->7$ & 0.4 & 4.81 \\
\hline & $7->8$ & 0.47 & 4.94 \\
\hline & $8->9$ & 0.53 & 3.11 \\
\hline \multirow{8}{*}{ 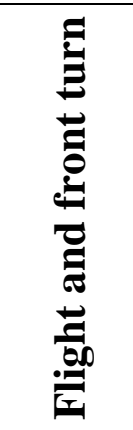 } & $9->10$ & 0.6 & 2.91 \\
\hline & $10->11$ & 0.67 & 4.18 \\
\hline & $11->12$ & 0.73 & 3.15 \\
\hline & $12->13$ & 0.8 & 2.4 \\
\hline & $13->14$ & 0.87 & 1.97 \\
\hline & $14->15$ & 0.93 & 2.1 \\
\hline & $15->16$ & 1 & 3.65 \\
\hline & $16->17$ & 1.07 & 3.56 \\
\hline
\end{tabular}




\begin{tabular}{|c|c|c|c|}
\hline \multirow{18}{*}{ 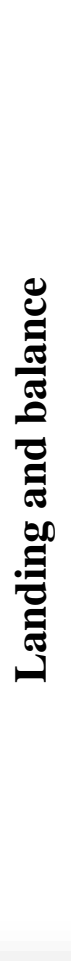 } & $17->18$ & 1.13 & 2.73 \\
\hline & $18->19$ & 1.2 & 4.26 \\
\hline & $19->20$ & 1.27 & 1.47 \\
\hline & $20->21$ & 1.33 & 1.52 \\
\hline & $21->22$ & 1.4 & 1.25 \\
\hline & $22->23$ & 1.47 & 0.92 \\
\hline & $23->24$ & 1.53 & 1.21 \\
\hline & $24->25$ & 1.6 & 3.11 \\
\hline & $25->26$ & 1.67 & 1.74 \\
\hline & $26->27$ & 1.73 & 0.56 \\
\hline & $27->28$ & 1.8 & 0.22 \\
\hline & $28->29$ & 1.87 & 0.44 \\
\hline & $29->30$ & 1.93 & 0.92 \\
\hline & $30->31$ & 2 & 1.21 \\
\hline & $31->32$ & 2.07 & 0.6 \\
\hline & $32->33$ & 2.13 & 1.05 \\
\hline & $33->34$ & 2.2 & 0.38 \\
\hline & $34->35$ & 2.27 & 1.3 \\
\hline
\end{tabular}

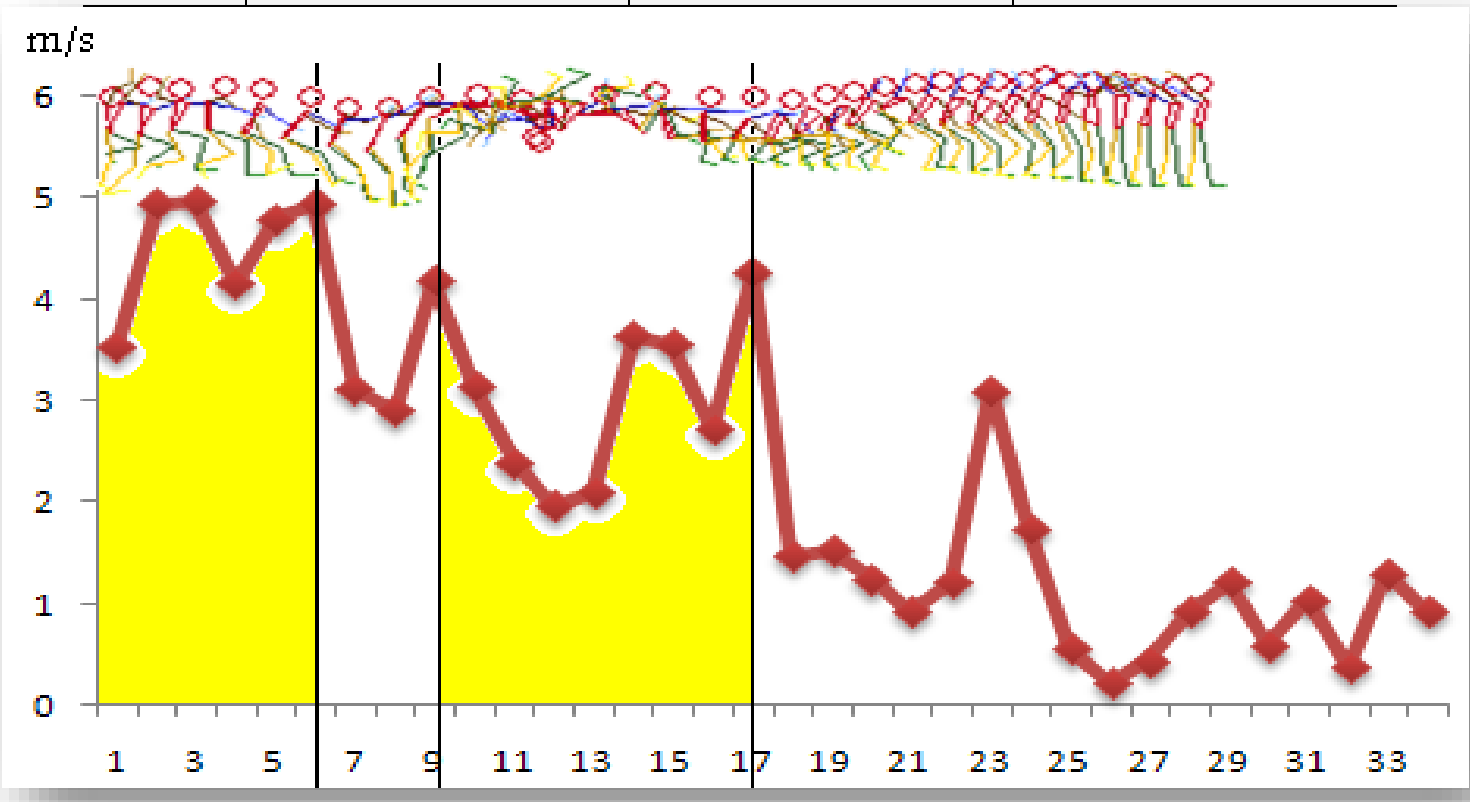

Figure (8): The obtained velocity curve (for the center of gravity of the body) during the performance of a skill (Salto Forward Tucked as a start) on the balance beam event - in female gymnastics - (model player)

Table (7): Summary of the resulted speed of body's center of gravity (model player) 


\begin{tabular}{l|c}
\hline Time & Resulted Speed \\
\hline Moment of leaving the ground & 4.95 \\
\hline Moment of enter the springboard & 4.81 \\
\hline Moment of leaving the springboard & 3.11 \\
\hline Moment of collision with the balance beam & 3.11 \\
\hline
\end{tabular}

It is clear from my tables (6) and (7) concerning the speed of the body's center of gravity that the player's speed at the moment of leaving the ground, the moment of entering the springboard, the moment of leaving the springboard and the moment of collision of the balance beam have reached $(4.95,4.81,3.11,3.11 \mathrm{~m} . / \mathrm{sec}$. ) respectively.

The researcher believes that there is a loss of speed on the springboard as the player exited the springboard at a speed less than the entry speed, which indicates that there is an amount of speed loss as a result of stopping resulting from the power of placing feet on the springboard of jumping and instantaneous stability without taking advantage of the reaction speed.

These results are consistent with the findings of Khaled Mohamed Ahmed Hodoud (2007), Soha Mohamed Abdel-Aal (2007), Ahmed Fawzi Yassin (2011), Fadi Omar Ali Al-Tanani (2013), Ahmed Mohamed Swailem (2016), Basma Sabry Al-Mashad (2016), Hussein Mohammed Hussein (2016), Ibrahim Ibrahim Shuaib (2018), Maha Ali Zain Al-Abidin (2018), Doaa Ahmed Mohamed Attia (2019), where they concluded to extract biomechanical variables for players during performing to develop specific specific quality exercises, and thus the researcher has answered the research question.

\section{Conclusions:}


In light of the research objectives and the results of the researcher and the results of the kinetic analysis, the researcher concluded the following:

\section{1- Conclusion of time distribution:}

- The period of time for the landing and balancing performance on the balance beam is approximately twice the time of Salto forward tucked.

- The landing and balancing represent the major share in the teaching and training process for the skill of Salto forward tucked as a start on the balance beam event.

\section{2- Conclusion of the distances}

- When performing the Salto forward tucked on the ground, the location of the landing on the balance beam with the feet is determined by the distance from the moment of pushing on the springboard to the moment of landing on the ground.

- The distance between the springboard and the moment of single leap from the ground is (1.3 time of the player's height).

- The height of the foot on the ground from the moment of leaving the ground to the springboard is low so that the player can push and exit at the highest height to make the rotation.

- The distance between the feet on the balance beam at the moment of landing from the Salto forward tucked represents (17\%) of the player's height.

- The exit of the ground or springboard is through the player's body and is almost perpendicular to the ground.

\section{3- Conclusion of the angular change:}

- The exit angles of the center of gravity are large for both land and springboard, while the entry angles are small on the springboard. 
- The big bend in the knee while hitting the balance beam enables the player to absorb to keep the balance.

- The moment of entry on the springboard happens while the arms are close to the body, so the player can use the two arms in swinging and help to balling and exit the springboard next to the pushing process.

\section{4- Conclusion of the speed:}

- The speed at which the player is launched from the ground in a single leap must be medium (appropriate) in order to be able to stop the process of rushing to the beam after the landing from rotation.

- There is a gradual decrease of speed from the moment of leaving the ground to standing on the balance beam.

\section{Recommendations:}

In light of the research objectives and the researcher's conclusios, the researcher recommends the following:

It is necessary to pay attention to study the kinetic and kinematic variables of the Salto Forward Tucked as a start for the gymnast to learn the movement details to reach the quality and efficiency of high technical performance.

Rely on studies of biomechanical analysis in building specific qualitative training programs in developing high performance skills in female gymnastics on the balance beam.

Conduct comparative studies to analyze the technical performance between world champions and the Egyptian national team players to identify aspects of strength and weakness and build appropriate training programs accordingly.

Conduct other analytical studies on advanced skills that have an impact on the overall technical performance scores. 


\section{References:}

1- Ahmed Fawzi Yassin (2011) Mechanical determinants as basis for setting purpose exercises for skills of angular attachment and hamd standing on the rings. MD Thesis, Faculty of Physical Education for boys in Cairo, Helwan University.

2- Ahmed Muhammad Swailem (2016) Biomechanical analysis of the skill of laying down for soccer goalkeepers as a basis for developing specific training. Ph.D. thesis, Faculty of Physical Education, Assiut University.

3- Basma Sabri Al-Mashad (2016) Using the biomechanical analysis to improve the skill level of glide kip to support on the uneven bars for female gymnasts. MD Thesis, Faculty of Physical Education, Mansoura University.

4- Doaa Ahmed Mohamed Attia (2019) Biomechanical indicators of (Ouch Jarry $\mathbf{x}$ Hari Joshi) skills as basis for developing specific training in judo. PhD thesis, Faculty of Physical Education, Mansoura University.

5- Fadi Omar Al-Tanani (2013) Kinematic changes to the skill of Salto forward Tucked on the vault and its relationship to some cognitive 
motor abilities in gymnastics for beginners. MD Thesis, Faculty of Physical Education, Mansoura University.

6- Gerd Hochmuth (1999) Biomechanics and Scientific Research Methods for sports Movements. translated by Kamal Abdel Hamid, Soliman Ali Hassan, The Book Center for Publishing, Cairo.

7- Hedayaht Ahmed Hassanein (1990) An analytical study of technical performance and special requirements of performance in the kinetic content on girls events for national team players. Journal of the First Scientific Conference, 4th edition, Faculty of Physical Education for Girls, Zagazig University.

8- Hussein Mohammed Hussein (2016) Mechanical variables as a basis for setting some specific exercises and their impact on the skill level of the individual offensive blocking for volleyball players. MD Thesis, Faculty of Physical Education, Assiut University.

9- Ibrahim Ibrahim Shoaib (2018) The effect of specific training in terms of some biomechanical indicators on the level of right side punch performance in the head among boxers. Ph.D. thesis, Faculty of Physical Education, Benha University.

10- Khaled Mohamed Ahmed Hodoud (2007) Biomechanical indicators as a basis for the design of specific training to improve the performance of Salto Backward Tucked and Salto Backward Tucked skills in gymnastics. $\mathrm{PhD}$ Thesis, Faculty of Physical Education, Assiut University.

11- Maha Ali Zain Al-Abideen (2018) Biomechanical analysis of the Free aerial walkover forward landing on one foot on the balance beam as an indicator for determining the technical performance characteristics and developing specific exercises. MD Thesis, Faculty of Physical Education, Beni Suef University.

12-Soha Mohamed Abdel-Aal (2017) Using the biomechanical analysis in preparing a training program for the skill of Salto Backward Stretched as a finish in the balance beam. Ph.D. thesis, Faculty of Physical Education, University of Alexandria. 
13- http://www.fig-

gymnastics.com/publicdir/rules/files/en_WAG\%20CoP\%202017-

2020.pdf

\section{Attachments}

Table (4): Technical description of the skill (Salto Forward Tucked as

a start) on the balance beam apparatus - in women gymnastics.

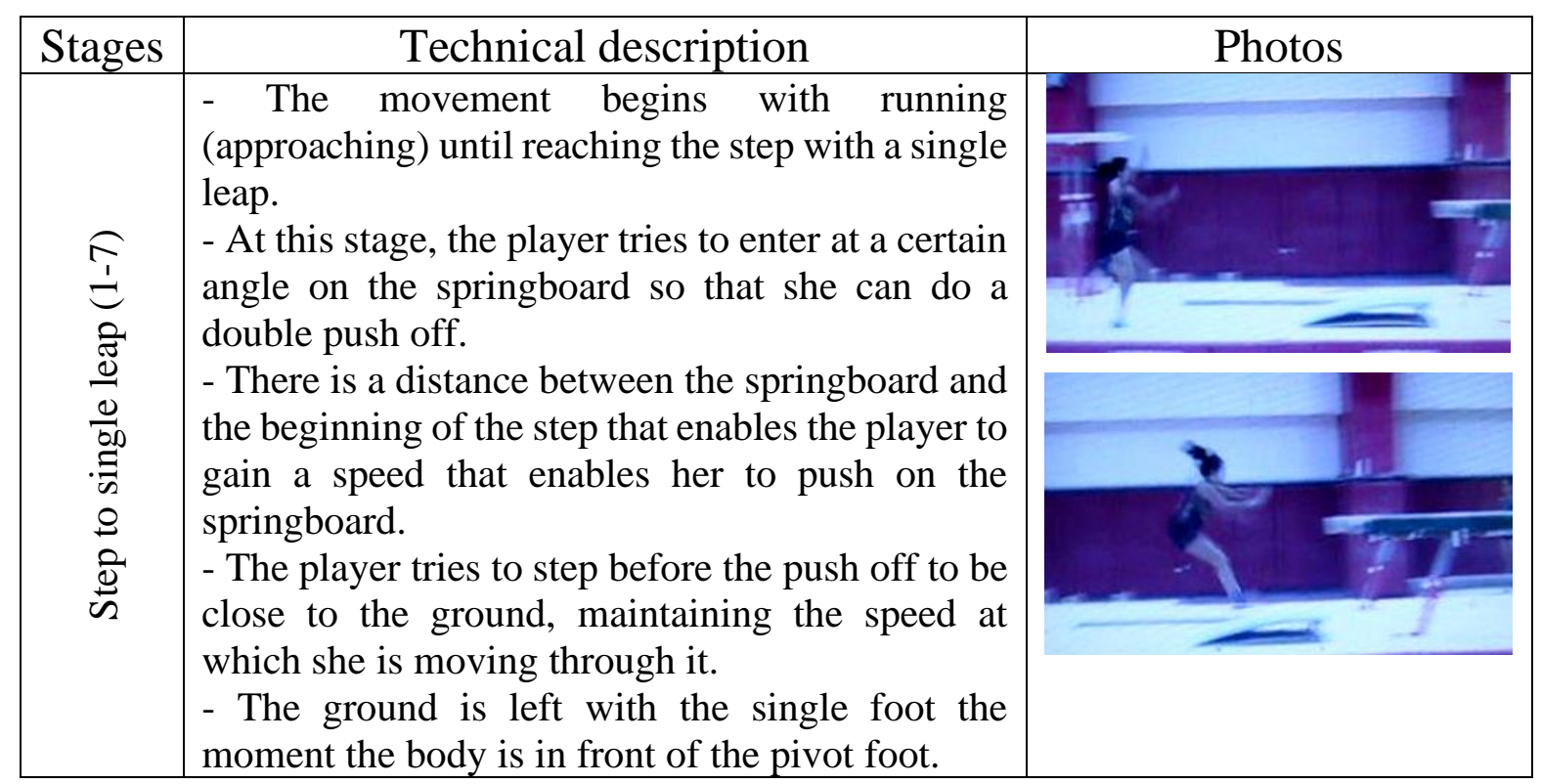




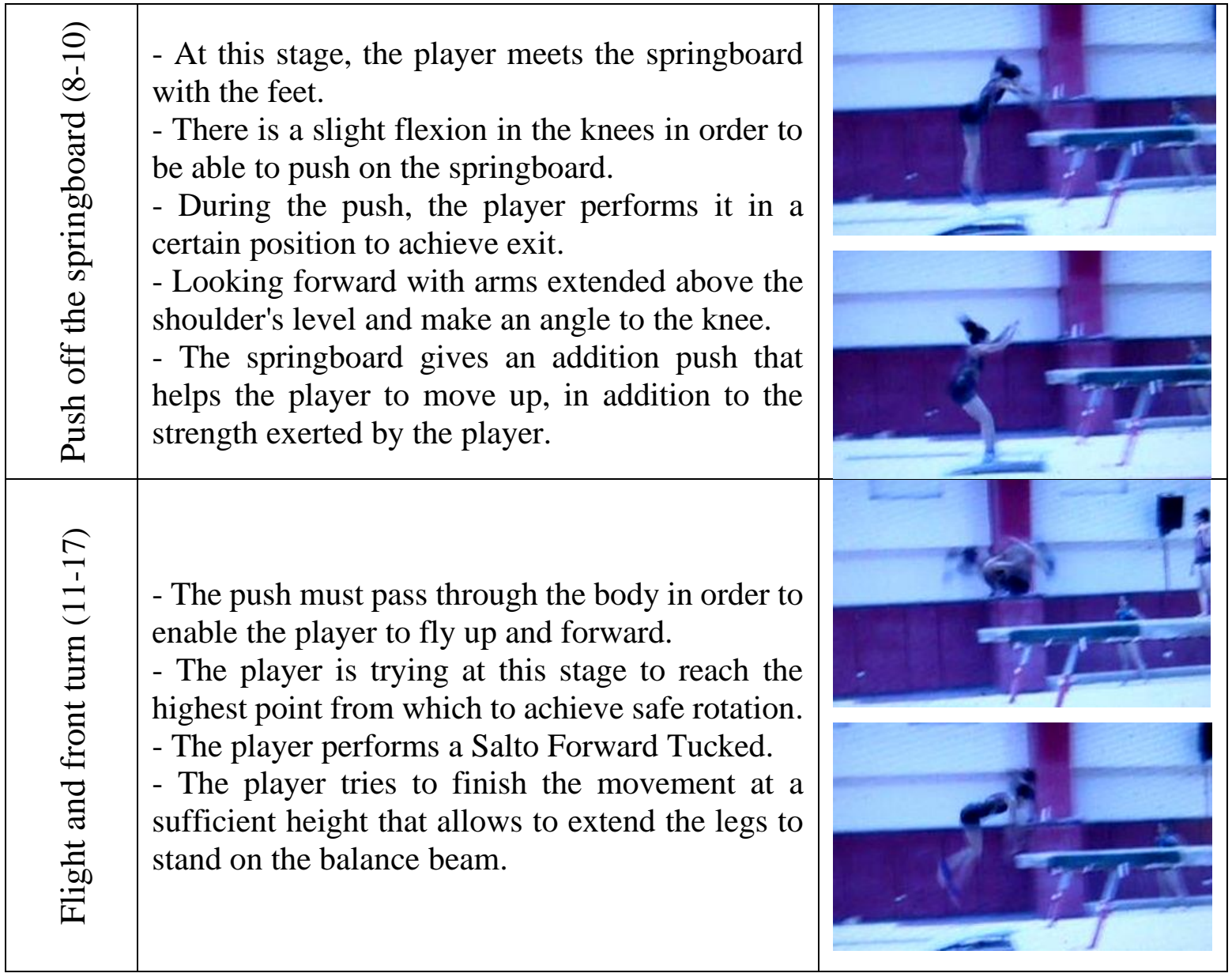

Table (5): Biomechanical characterization of the skill (Salto Forward Tucked

as a start) on the balance beam apparatus - in women gymnastics.

\begin{tabular}{|c|c|c|}
\hline Stages & Technical description & fig \\
\hline 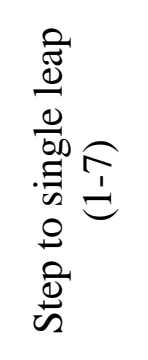 & $\begin{array}{l}\text { - Phase time } \\
\text { - Horizontal distance of foot (step length) } \\
\text { - Tilt of the body on the ground the moment of leaving (jumping angle). } \\
\text { - The speed at which the player moves. } \\
\text { - The height of the center of gravity of the body at the top of the step } \\
\text { track and the moment of leaving. } \\
\text { - Angle of exit from the ground. }\end{array}$ & \\
\hline 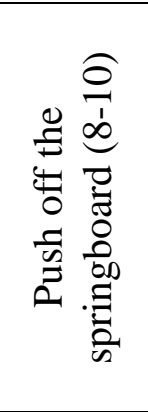 & $\begin{array}{l}\text { - Phase time } \\
\text { - Horizontal distance of feet (position of feet on the springboard). } \\
\text { - Angular change of the knee. } \\
\text { - Horizontal and vertical distance to center of gravity (position of center } \\
\text { of gravity from feet). } \\
\text { - Angular change of shoulder, thigh, knee. } \\
\text { - The momentum on the springboard. } \\
\text { - The resulted ability by the body's center of gravity on the springboard. }\end{array}$ & \\
\hline
\end{tabular}




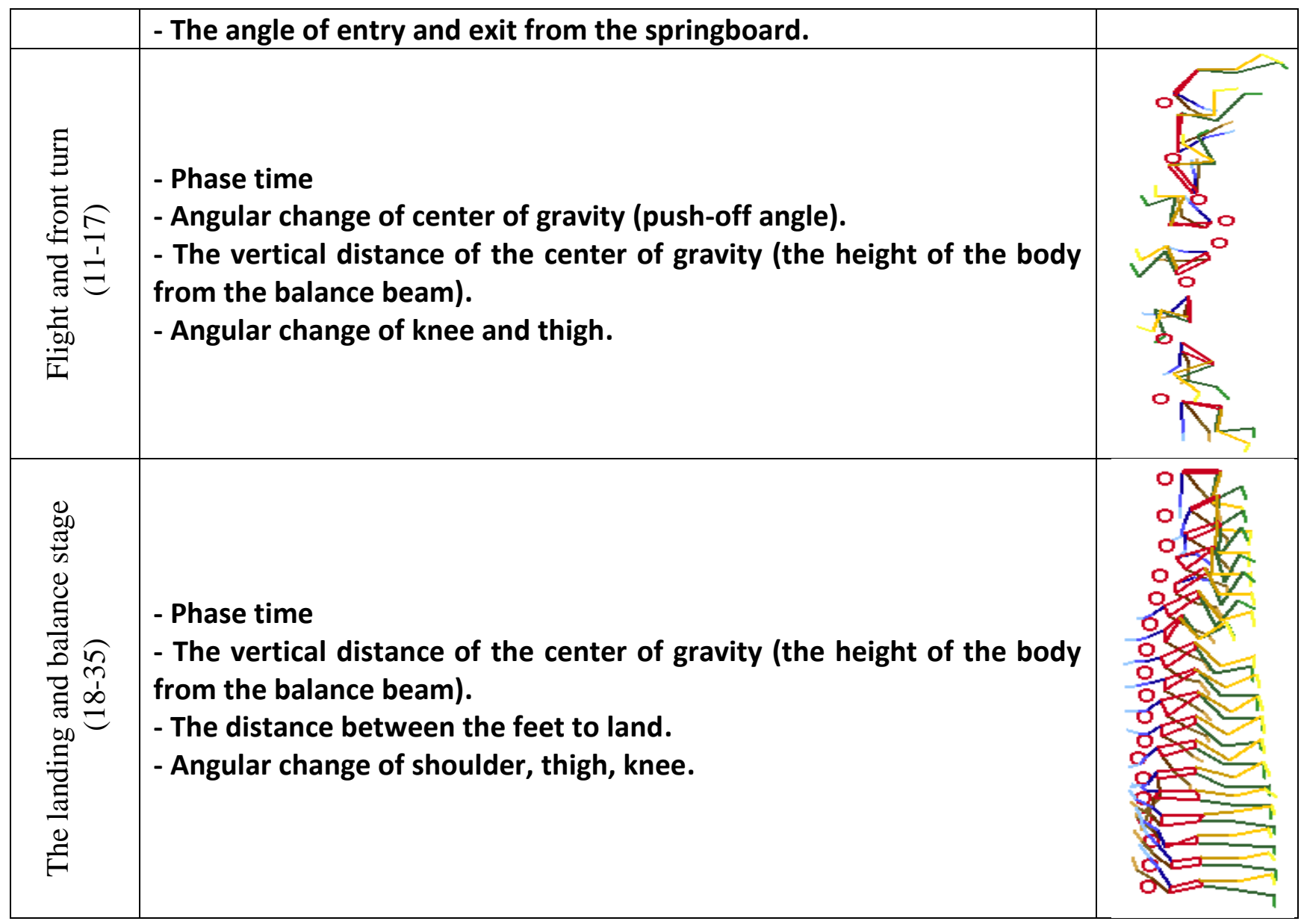

